\title{
Effects of The Presence of A Cell Phone And Exposure To Natural Environments On Remote Associates Task Performance
}

Wenjuan Liu ( $\nabla$ w.liu_acp@hus.osaka-u.ac.jp )

Osaka University

Akihiko Dempo

Seikei University

Tsukasa Kimura

Osaka University

Tomoya Kawashima

Osaka University

Kazumitsu Shinohara

Osaka University

Research Article

Keywords:

Posted Date: February 1st, 2022

DOI: https://doi.org/10.21203/rs.3.rs-1300998/v1

License: (c) (i) This work is licensed under a Creative Commons Attribution 4.0 International License. Read Full License 


\section{Abstract}

In today's advanced information society, creativity in work is highly valued, and there is growing interest in the kinds of work environments that produce more creative outcomes. Recent researchers have demonstrated that when environmental factors change a worker's attentional state to a diffused state, the worker has access to more information than usual, which can contribute to creativity. Here, we examined whether manipulating environmental factors (the presence of a cell phone and exposure to natural environment) that could affect such attention states would improve performance on the Remote Associates Task, a measure of creativity. Our results showed that the presence of a cell phone increased creative performance regardless of immersion in natural environment. In contrast, exposure to nature did not facilitate creative performance; instead, feelings of pleasure increased, and frustration decreased. These results suggest that the presence of a cell phone can enhance creativity by influencing workers' attentional states. The current study provides a meaningful approach to enhancing creativity by modulating attentional states through environmental factors. It also highlights the essential features of environmental factors that can moderate creative abilities.

\section{Introduction}

In today's advanced information society, it is now both possible and desirable to acquire information anytime and anywhere. Because mobile devices such as cell phones are by their definition portable, users can obtain and exchange information whenever they choose as long as Internet access is available; phones have also become the most common way to connect with others, primarily in the form of posts and exchanges on social network platforms. Meanwhile, cell phones are used for not only personal but also work-related purposes ${ }^{1,2}$ because of their great convenience. Cell phones today are considered essential for communication and not kept aside during both work and non-work hours. In addition, with the development of internet communication technology, work styles that are not restricted by location are being realized, and intellectual workers are becoming engaged in work in a variety of environments ${ }^{3}$. This change in work styles has increased the importance of cell phones at work.

In an advanced information society, simple and mechanical tasks will be automated, while human workers will be required to engage in tasks that require a high level of creativity ${ }^{4-8}$. For this reason, there has been a great deal of interest in enhancing the creativity of workers in various environments. In this context, researchers have suggested that adding situational factors can enhance creativity ${ }^{9}$. For instance, physical orderliness (e.g., how well things are stored in the environment) is one environmental characteristic that enhances creative behaviors. Vohs and colleagues ${ }^{10}$ reported that participants in an environment with low orderliness performed better in the Alternative Uses Task ${ }^{11}$, which asks participants to think of as many uses as possible for a simple object such as a brick, a shoe, or a paper clip. In addition, Zhu and colleagues ${ }^{12}$ found that participants in moderate noise $(70 \mathrm{~dB})$ were able to perform the creativity task better than those in high $(85 \mathrm{~dB})$ and low $(50 \mathrm{~dB})$ noise. With this noise study, the researchers also explored the underlying mechanism of the impact of noise on creativity; their findings 
suggested that moderate levels of everyday background noise can induce processing disfluency and activate an abstract style of cognitive processing that increases creativity. It is implied that manipulating attention through situational factors can drive optimal performance of creative tasks in the workplace. Based on the theoretical framework of the relationship between creativity and attentional function (i.e., nonfocused attention), we aimed to explore possible ways to improve creativity through situational factors in the present study.

People in a nonfocused attentional state are more creative than those in a focused state of attention ${ }^{13-17}$. Researchers on related studies ${ }^{18,19}$ have found that those who performed better on a creative task ${ }^{20,21}$ (e.g., Wallach-Kogan creativity tasks and Torrance Tests of Creative Thinking) showed poorer performance on cognitive tasks (e.g., divided attention task and the Stroop task). This is because people who have better attention control suppress task-unrelated information and maintain their focus on taskrelated information ${ }^{22}$; in those findings, the creative people were more likely to notice information that was not relevant to the task and thus to be distracted. In support of this conclusion, in other studies, lower ability to inhibit the influence of task-irrelevant stimuli was associated with higher creative performance 23,24 . Moreover, researchers have found that highly creative participants are not only more likely to be distracted by irrelevant information but also able to derive potential cues from that information ${ }^{15}$. This suggests that acting creatively lies in being able to perceive and utilize more taskunrelated information by loosening the attentional filter, which passes only task-related information. This attentional state is referred to as unfocused attention, nonfocused attentional state, diffuse attention, and leaky attention ${ }^{13}$.

Unfocused attention is not the result of personal characteristics of highly creative people but is observable in general populations when external factors facilitate the unfocused state. One of the factors that cause nonfocused attentional states is distraction, in which attention is drawn to an object unrelated to the task. For instance, in contrast with young adults, older adults who are vulnerable to distraction ${ }^{25}$ can use "distracting" information to obtain cues that are actually relevant to solutions ${ }^{26}$. Similarly, Jarosz and colleagues ${ }^{27}$ found that intoxicated individuals (i.e., blood alcohol content of approximately 0.075 ) generated more solutions to the remote associates test ${ }^{28}$ in less time than did nonintoxicated individuals. These results indicate a direct relationship between unfocused attention and creativity and suggest that inducing unfocused attention with external factors can foster creativity.

In the workplace, cell phones may trigger nonfocused attentional states, which in turn can foster creativity. In one recent study, the presence of cell phones caused cognitive failures ${ }^{29}$, and in other studies, the presence of a cell phone induced poor performance on cognitive tasks by reducing attentional resources available for the task ${ }^{30,31}$. Such effects can be attributed to attentional capture by external stimuli ${ }^{30}$, unconscious task-irrelevant thoughts ${ }^{32,33}$, and/or being in the state of permanent readiness to respond to one's smartphone ${ }^{34}$. That is, the presence of cell phones can moderate the distribution of attention, reducing the amount of attentional resources directed to the task while slightly increasing the amount of attentional resources allocated to task-irrelevant stimuli. In other words, the 
presence of a cell phone can make users more sensitive to stimuli and information that is not task-related -that is, more easily distracted. In real-world circumstances, a person with a cell phone nearby might be in a nonfocused attentional state; therefore, we theorized that the presence of a cell phone could shift employees into unfocused attention.

Another way to create a state of nonfocused attention is through contact with nature. In natural environments, the variety of natural stimuli (e.g., waterfalls, birdsong, wind, and green trees) can involuntarily attract our attention ${ }^{35}$, and this attention capture is effortless; findings indicate that immersion in nature can modulate attention. Researchers found higher rates of gaze shifting in natural environments than in urban ones ${ }^{36}$, and other researchers found that after exposure to nature, autonomic arousal (heart rate) and the efficiency of spatial attention both decreased ${ }^{37}$. Accordingly, the attentional state in an environment with a variety of natural stimuli is more likely to be dispersed and closer to nonfocused than will be the case in environments without stimuli (e.g., an office). Therefore, we expect that exposure to nature will have the similar effect of distracting attention from the main task as the effect of the presence of a cell phone.

Indeed, several studies have shown that exposure to nature increased creativity ${ }^{38-42}$. Both wild (real nature) and indoor (pseudo-nature with natural elements) natural environments can induce the effect of exposure to nature, although the effect in an indoor environment was only evident among female participants ${ }^{40}$ and is unlikely to induce as large an effect as that from wild natural environments. The effects of exposure to nature on cognitive activity are generally interpreted in terms of Attention Restoration Theory ${ }^{35}$ (a variety of natural stimuli attract involuntary attention, thus restoring voluntary attentional resources) and Stress Reduction Theory ${ }^{43,44}$ (directing attention to vigorous, green natural stimuli induces positive emotions and low stress). However, while many studies have shown that attentional recovery by exposure to nature can facilitate the performance of typical cognitive tasks that assess lower-order attentional functions such as working memory and selective attention ${ }^{45}$, these improvements in attentional functioning have often had negative impacts on creativity ${ }^{46}$. Thus, it is more likely that the effects of exposure to nature on creativity that depend on distractive (i.e., nonfocused) attentional states can be achieved by mildly directing attention to a variety of stimuli rather than restoring attention.

In contrast to common interpretations, we assumed in the current study that exposure to nature would improve creative abilities by adjusting participants' attentional states to be nonfocused. Taken together, we had two goals with the current study: examining whether the presence of a cell phone would enhance creativity and examining the relationship between creativity and exposure to nature, which is known to affect creativity.

\section{Method}


Participants. The participants were 32 adults recruited by a participant-recruiting agency $(M=21.34, S D=$ 2.42, 16 men, 16 women). Twenty-seven were right-handed, four were left-handed, and one was ambidextrous. This study was approved by the Behavioral Research Ethics Committee of the School of Human Sciences, Osaka University in Japan (HB019-080). Written informed consent was obtained from all participants. All methods were performed in accordance with the relevant guidelines and regulations.

Experimental apparatus and manipulations. Figure 1 displays the experimental apparatus. A video player (Panasonic, DP-UB9000) presented videos of natural scenes provided by LandSkip Inc. (forest, waterfall, coast; https://www.landskip.jp/) on a 65-inch LED monitor (JAPANNEXT, JN-V6500UHDR) located 120 $\mathrm{cm}$ from the participant's seat. A stereo system (Pioneer, 5.1ch HTP-S363) with surround sound speakers (Pioneer S-H100) was used to project the videos' stereoscopic sound at a volume of $70 \mathrm{~dB}$. A breeze was created by a small fan placed on the side of the desk. The computer (Mouse, MB-B505S-M2S1) was set in the center of the desk $(120 \mathrm{~cm}[\mathrm{~W}] \times 60 \mathrm{~cm}[\mathrm{H}])$, and the software PsychoPy (ver. 1.83.04, Peirce, 2007, 2009) presented the task stimulus. A smartphone (Apple iPhone 11) was placed on the side of participants' dominant hand.

Skin conductance level (SCL) represents the tonic level of a skin response and reflects general changes in arousal ${ }^{47}$. Skin conductance was recorded using an electrodermal activity amplifier MaP1720CA and unit AP-U030 (Nihonsanteku) with two circular electrodes (1-cm diameter, Mets Inc.); these were attached to the medial phalanx surfaces of the middle and index fingers of the nondominant hand. These data were recorded using input monitor software (Nihonsanteku), and the sampling rate was $500 \mathrm{~Hz}$ with a $0-15 \mathrm{~Hz}$ digital band-pass filter applied.

Search task. The search task was a dummy task and conducted before the remote associates test to make participants aware of the presence of the cell phone. Participants were given a list of 10 Chinese characters and asked to use the designate phone to find 10 common two-word phrases (e.g., " $\triangle \mathbb{Q}^{\prime}$ ": inside court) that contained the given characters (e.g., " $\nabla$ ": inside); they had 5 min to collect phrases and write them in the answer column.

Remote associates test (RAT). Creativity was measured by the Japanese version of the RAT ${ }^{48}$, which was used in previous study ${ }^{38}$ as a creativity task. The RAT requires participants to find a single associated word which can be combined with each of the given three words (either being placed before it or after it) to make a common word or phrase. For example, a RAT items including three words (e.g., dream, break, light) can be solved by the associated word (in this case "day"). The Japanese version of RAT has the similar rules as the English version that participants were presented with three Chinese characters $\left(2.5^{\square} \times\right.$ $2^{\square}$ visual angle) on the center of a screen and asked to write down a common Chinese character associated with each presented character.

Assessing affect and mental workload. To investigate the affective impacts of the presence of a cell phone and of exposure to nature, we used the Positive and Negative Affect Schedule ${ }^{49,50}$ (PANAS), to assess the changes in affect between before and after participants completed the RAT with or without a 
cell phone nearby. For the current study, a native Japanese speaker translated the PANAS, and the internal reliability was high: Cronbach's alpha $=.847$ and .844 for positive affect and negative affect, respectively.

To determine what internal processes are activated by exposure to a natural environment to improve performance on a creativity task, it is necessary to measure affect ${ }^{51}$ (valence and arousal), physiological response to stress, and mental load. Here, we measured mental load ${ }^{52}$ with 5 items from the NASA TLX ${ }^{53}$ (desire for knowledge, own performance, frustration, effort, and overall workload) as a subjective assessment and measured stress based on physiological response, specifically skin conductance.

Experimental flow and procedure. Participants took part in experiments over two days, one in the presence of a smart phone and the other in absence for counterbalance. Only participants who attended in exposure to nature condition completed the two days experiment in an environment with natural elements, while others in control (without exposure to nature) condition, they completed the two days experiment in an environment without natural elements. Based on a preliminary experiment, we set the RAT items in each smart phone condition at identical, moderate difficulty (i.e., average correct rate of each task set: $60 \%$ ). In addition, the order of the RAT items in each phone condition was all randomized. The procedures for both days' experiments were identical except that on the first day, the participants were required to complete a practice task. The experimental flow for one day is shown in Figure 2.

After participants finished the practice task in RAT, electrodes were pasted on the second joints of their forefingers and middle fingers on their nondominant hands, and then the SCL recording began. Before the participants entered the search task, the SCL recording lasting 3 mins (i.e., front rest) were used as the baseline. Next was the main task session: in the nature-present condition, a video of natural scenes and related settings were presented (see the Experimental Apparatus and Manipulations section). The main experiment had two sets of tasks; one task set included a phone search task and two blocks of the RAT, with 3 min of rest between the blocks. In the smartphone-absent condition, the experimenter took away the phone after the search task and put a mobile battery on the table that was similar in size and weight to the phone; this time, participants could see and were able to touch the battery but not use it.

In the two blocks of the RATs ( 9 trials per block), participants were required to complete them successively and had a 1-minute rest interval between the blocks. In one trial, there is a RAT thinking section with a $45 \mathrm{~s}$ limit, followed by a RAT answering section with no time limit. In the thinking section, the characters were presented for $45 \mathrm{~s}$, and the participants were asked to think of a correct answer within that time. In the answering section, the instructions for the answer method and the number of the current trial were presented instead of the characters. If the participants could find the answer within $45 \mathrm{~s}$, they were asked to press the space key to enter the answering section and then write their answers on the designated response sheet. If the participants failed to find the correct answer in $45 \mathrm{~s}$, the screen automatically switched to the answering section. The participants were instructed not to continue thinking about the RAT after the screen switched. 
The participants completed the PANAS ${ }^{53}$ four times: before the first RAT block, after the second, before the third, and after the fourth. Participants also answered questions about mental load ( 5 items from NASA-TLX) and about their feelings toward natural environments (9-point scale measuring valence and arousal) after the experiment. On the second day, participants completed the Problematic Use of Mobile Phone (PUMP) questionnaire ${ }^{54}$ (translated by a native Japanese speaker) and the question of demographic information.

Experiment design and hypothesis. This experiment followed a 2 (exposure to nature: absent or present, varied between participants) $\times 2$ (phone presence: present or absent, varied within participants) factorial design. The hypothesis of this study is as follows:

H1: (a) Participants with a smart phone nearby will perform the creative task better than participants who do not have a phone nearby (b) The score of negative affect will increase in the presence of a cell phone.

$\mathrm{H} 2$ : Participants will perform the creative task better in a nature present condition than in a nature absent condition.

H3: The participants will experience (a) less mental workload, (b) stress, and (c) be more relaxed in a nature present condition. This difference in subjective feelings will be reflected in a) All or part of the items from NASA -TLX would decrease; b) SCL will change less in a nature present condition; and c) The score of valence will increase and the score of arousal would decrease in a nature present condition irrespective of cell phone presence.

In summary, performance of the RAT will be higher when a cell phone is present, nature elements are present, or both are present than when neither a phone nor nature elements are present. Additionally, we explored how these interactions would affect creativity performance.

\section{Results}

Data analysis. We discarded data from two participants because a program error was found for one participant and the other participants misunderstood an instruction for the RAT and could not follow the appropriate procedure. Thus, we analyzed data only on the remaining 30 participants.

To represent physiological arousal level changes, we calculated the averages of SCL values for front rest, intermediate rest, and blocks of the RATs ${ }^{55}$. Reactivity in response to every block was calculated by subtracting baseline SCL from SCL during the RAT blocks, which combined nature exposure (absence or presence) and phone (presence or absence) conditions; front rest as the baseline SCL corresponded to blocks 1 and 2, and intermediate rest corresponded to the remaining blocks.

To confirm whether the individual differences in cell phone usage dependence affect the observed effect of exposure to nature on creativity, the PUMP score between the nature absence and presence conditions were analyzed for normality (Shapiro-Wilk normality test: mean $_{\mathrm{abs}}=127.20, \mathrm{~W}_{\mathrm{abs}}=0.92, p_{a b s}=0.19$; 
mean $_{\text {pre }}=116.13, \mathrm{~W}_{\text {pre }}=0.97, p_{\text {pre }}=0.89$ ), equality of variances (F-test: $F(1,14)=0.80, p=0.69,95 \% \mathrm{Cl}$ $0.27-2.40$ ), and differences in means (T-test: $t(28)=-0.93, p=0.36, \mathrm{IC} 95 \%=-35.41-13.28, d=0.34$ ), respectively. These results show that the two groups of PUMP scores followed a normal distribution with equal variance and no difference between the means was observed, indicating that any influence we observed between nature absence and presence could not be attributed to the individual inference of cell phone usage.

The angular transformed values of the ratio of correct RAT response and reaction time (key press reaction time in the thinking section of the correct answer) were analyzed using two-way analysis of variance (ANOVA) with the presence of a smart phone and exposure to nature as factors. We analyzed SCL using a three-way ANOVA with phone presence, exposure to nature, and RAT block as factors. The score of negative affect and positive affect was analyzed by a three-way ANOVA with measurement timing (marked as P1, P2, P3, and P4), phone presence, and exposure to nature as factors. Subjective ratings other than PANAS were analyzed using a two-way ANOVA as in the analysis of hit rate. All degrees of freedom were adjusted using Chi-Muller's epsilon. All the multiple comparisons used Shaffer's multiplecomparison procedure. The details of the nonsignificant results are available at http://osf.io/x93j6/? view_only=8c8ed1f4bd294f8c928c3b4226fd6907.

RAT performance. Figure 3 shows the ratios of correct responses (left); the main effect of phone presence was significant, $F(1,28)=11.06, p<0.01, \eta^{2}=0.0625$, whereas the main effect of exposure to nature was not significant, $F(1,28)=0.30, p=0.59, \eta^{2}=0.0083$. The two-way interaction for nature and phone presence was also not significant, $F(1,28)=1.46, p=0.24, \eta^{2}=0.0083$. Figure 3 (right panel) shows that we observed no significant difference in either main effects or interactions in the results for reaction time. Irrespective of nature condition, the participants with a smart phone nearby generated more correct responses than did those who had only a mobile battery present. In short, the presence of a cell phone increased creativity task performance, supporting $\mathrm{H} 1 \mathrm{a}$.

SCL change. The main effect of the block was significant, $F(1.35,37.85)=9.24, p<0.01, \eta^{2}=0.0751$, whereas the main effects of phone presence, $F(1,28)=2.38, p=0.13, \eta^{2}=0.0129$, and exposure to nature, $F(1,28)=1.05, p=0.31, \eta^{2}=0.0156$, were not. The two-way interaction for the block and phone presence was significant, $F(2.24,62.6)=3.26, p<0.05, \eta^{2}=0.0086$, and the simple main effect of block was significant in the phone-absent condition, $F(1.66,46.61)=12.54, p<0.01, \eta^{2}=0.1092$; this latter finding indicated that SCL changed more in block $1(6.53 \mu \mathrm{S})$ than in blocks $3(3.57 \mu \mathrm{S})$ and $4(2.26 \mu \mathrm{S}$; $p s<.05)$; SCL in blocks 2 and 3 was also higher than that in block 4 ( $p s<.05)$. Whereas the simple main effect of the block was marginally significant in the phone-present condition, $F(1.48,41.42)=3.53, p=$ $0.05, \eta^{2}=0.0498$, there were no significant differences between the blocks. The simple main effect of phone presence was only significant in block $2, F(1,28)=5.89, p<0.05, \eta^{2}=0.0334$, which indicated that $\mathrm{SCL}$ changed more in the absence of a smart phone than in its presence in that block $(3.56 \mu \mathrm{S}>1.81 \mu \mathrm{S})$. In the phone-absence condition, the SCL changes decreased over time, but we did not observe this 
tendency when the phone was present. Meanwhile, there was no significant difference between nature conditions; thus, $\mathrm{H} 3 \mathrm{~b}$ was not supported. Figure 4 graphically presents the SCL changes.

Subjective affect ratings.Figures 5 and 6 presents the PANAS results for affect ratings in the presence or absence of a nature environment. No main effects or interactions were significant for positive affect, whereas for negative affect (one scale of the PANAS), the main effect of measurement timing was significant, $F(2.58,72.12)=10.05, p<0.001, \eta^{2}=0.0523$; neither the other main effects nor the interactions were significant. Participants showed higher scores for negative affect after completing the first half of the tasks (P1 < P2, P4; P3 $<$ P4, ps $<0.05)$ that decreased after rest (P2 > P3, $p<0.05)$; moreover, the negative affect increment in the first half of the tasks was larger than that in the second half $(\mathrm{P} 1=\mathrm{P} 3, \mathrm{P} 2>\mathrm{P} 4, p<0.05)$. These results did not reflect any difference due to the presence of a smart phone; thus, $\mathrm{H} 1 \mathrm{~b}$ was not supported.

Figure 7 displays the remaining subjective ratings for all participants. For valence, the main effect of exposure to nature was significant, $F(1,28)=5.40, p<0.05, \eta^{2}=0.0903$, but not that for phone presence, $F(1,28)=0.65, p=0.43, \eta^{2}=0.0100$, which reflected that participants felt more pleasure from the presence of nature than they did in its absence irrespective of phone presence conditions. No two-ways interaction was detected, $F(1,28)=0.20, p=0.66, \eta^{2}=0.0031$. For arousal, neither main effect nor interaction was significant. Therefore, $\mathrm{H} 3 \mathrm{c}$ was partially supported.

For desire of knowledge, the main effect of phone presence was marginally significant, $F(1,28)=3.38, p$ $=0.07, \eta^{2}=0.0244$, whereas the main effect of exposure to nature was not, $F(1,28)=0.26, p=0.61, \eta^{2}=$ 0.0071 . No two-ways interaction was detected, $F(1,28)=1.62, p=0.21, \eta^{2}=0.0117$. The participants' desire for knowledge was more conscious when the phone was absent than when it was present, which indicated that the mental demand without a smart phone was higher, and the participants had to attempt to retrieve more knowledge to arrive at a correct answer.

For frustration, both the main effect of exposure to nature, $F(1,28)=4.38, p<0.05, \eta^{2}=0.0782$, and the main effect of phone presence, $F(1,28)=4.54, p<0.05, \eta^{2}=0.0588$, were noted. No two-ways interaction was detected, $F(1,28)=0.10, p=0.75, \eta^{2}=0.0014$. Participants showed more frustration in the absence of nature than in its presence and more frustration in the absence of a smart phone than in its presence. For the remaining subjective ratings, all main effects and interactions were nonsignificant. Figure 7 presents all the mean subjective ratings. In the overall rating of five items from the NASA task load index, mental load in the form of frustration was lower in the nature environments, which partially supported H3a.

\section{Discussion}

The main aim of the current study was to determine whether the presence of a cell phone and/or exposure to nature would affect creativity. In this study, participants with a smartphone nearby performed better on RATs (Figure 3a) and reported less frustration and less desire for knowledge than did 
participants with only a mobile battery nearby (Figure 7c, f); that is, the mere presence of a cell phone fostered creativity. Regarding the effects of exposure to nature, participants reported more pleasure and less frustration in its presence than in its absence, although we did not observe related nature benefits in creative performance.

The first and most vital finding in the current study is that a cell phone presence after using it facilitated the performance of the sequent creative task (i.e., RAT: Figure 3a), indicating that the presence of a cell phone can increase creative outcomes. This result could be induced by adjusting the participants' attentional state to a nonfocused one. A cell phone can be used as an extended technological device to support offloading cognitive demand ${ }^{56,57}$ (e.g., excessive information processing). When people engage in a task utilizing a cell phone, their attention may be diffused to plural information sources rather than converging to a single source because diffused attentional state has many advantages (e.g., increased efficiency of information processing). In the current case, it is plausible that the state of diffused attention that was induced by using a cell phone was maintained during the subsequent creative task in the phone present condition. Therefore, it is quite possible that the presence of a smart phone distracted the participants' attention but simultaneously led to unfocused attention that enabled them to access more information to perform better in the creativity task. Notably, a previous study ${ }^{58}$ that used a luminance detection task directly observed distraction by cell phone, which was presented through a similar method as the current study. That is, although the current study did not measure the available attentional resources during the creative task directly, it can be assumed that distraction is also caused by the cell phone in this study.

Further, it was found that participants reported a lower subjective mental load (reflected in frustration and desire for knowledge) as they completed the RATs in the presence of the smart phone (Figure 7c, f), suggesting that they were aware to some extent that the presence of a cell phone facilitated their cognition. Moreover, we found that the SCL changes decreased gradually as the task progressed but only in the absence of a cell phone (Figure 4). This finding suggests that the presence or absence of a smart phone has some effect on arousal, but the underlying mechanism is currently difficult to interpret. Future work is necessary to further examine the relationship between the presence of a smart phone and corresponding changes in physiological arousal level.

In this study, it is not clear whether the facilitative effect of the presence of cell phones on creativity is stronger than the disruptive effect produced by distraction. Although multiple researchers have observed negative effects of cell phone presence ${ }^{28-31,59}$, many others have concluded that it is difficult to replicate the effects of a cell phone's presence and that the effects can even be described as weak ${ }^{60-63}$. It is likely that other potential factors (e.g., task meaningfulness to participants and individual differences in emotion-related impulsivity) can moderate or limit the negative effects such that they are not evident in a wide range of situations. The next important matter is determining the relative strength of the creativityfostering effects of the presence of cell phones compared with their disruptive effects on attention, and it is also necessary to consider how to increase the facilitative effects while limiting distraction. 
Inconsistent with related studies on the benefits of exposure to nature for creative outcomes ${ }^{37-40}$, we found no significant influence of natural environments on creative performance, while we only observed the moderated effect on the affective aspect. The positive mood changes are reflected by the self-rating of valence and frustration, so participants in a natural environment felt more pleasant and were able to reduce the negative affective consequences that may accompany performing a task (i.e., RAT) with a relatively high cognitive load. Increased positive mood as one of the typical affective benefits of exposure to real natural environment ${ }^{64}$ (e.g, forests and park) was observed in the current indoor natural setting (Figure 7a, f), implying that the simulated indoor natural environment has the capability to elicit similar affective benefits as the real natural environment. However, the expected improvements in creative performance through exposure to nature, as in Atchley's ${ }^{37}$ study, were not evident. One possible explanation for this discrepancy is the time constraints of the current study. While Atchley ${ }^{37}$ did not place limits on respondents' time to answer, we imposed a 45-s time limit, instructing participants to follow the given instructions in producing their responses. Only responses that were made within this time limit were considered correct. Creative thinking is regarded as a high-order cognitive process not driven by speed of information processing ${ }^{65}$; hence, unlimited response duration can provide an opportunity for individuals to maximize their creative potential in the performance of tasks measuring creativity. That is, the observed facilitation effect of exposure to nature under the condition of no time limit might be larger, compared with a time limit situation such as that of the current study. Thus, we speculate that this time limitation may have weakened the effect of exposure to nature observed at the behavioral level. Future study is needed to consider time in addressing the effects of an indoor environment with nature elements on creativity.

The current study has several limitations. First, we used a designated cell phone rather than each participant's own cell phone to strictly control factors such as phone brand, series, and color. However, the impact of their own phones should be more realistic and richer, given the complexity of the intrinsic causes of cell phone presence effects. Second, although we believe that the presence of a cell phone affects creativity by altering one's attentional state to allow processing of more task-irrelevant information, we did not measure the ability of participants to generate information that is slightly less relevant to task such as remote associated words, which was measured in a related study ${ }^{66}$. In other words, the current results alone do not rule out the possibility that cell phones are fostering creativity in other ways (e.g., affecting motivation). Therefore, we can only say that the current findings provide indirect evidence, and further research is needed to directly confirm the underlying mechanism of the impacts of a cell phone's presence on creativity.

The present study provides experimental evidence that the presence of a cell phone can positively affect creativity. Considering that this influence was tested in settings that replicate real-world work environments, our findings possibly reflect a more comprehensive expression of the impacts of a cell phone's presence and will contribute to a better understanding of the impacts of cell phones on performance and creativity in work environments. With the current study, we also added to the body of 
knowledge on fostering creativity by demonstrating that so-called nonfocused attentional state might be crucial to linking situational and environmental factors to increased creative outcomes.

\section{Data Availability}

Data and scripts are available on the Open Science Framework: http://osf.io/x93j6/? view_only=8c8ed1f4bd294f8c928c3b4226fd6907.

\section{Declarations}

\section{Acknowledgements}

We thank LandSkip Inc. (https://www.landskip.jp/) for providing the nature videos. We are also grateful to Dr. Yohko Hirokawa for implementing the experiment.

\section{Author contributions}

$W L, A D$, and $K S$ contributed to the study conception and design. WL contributed to the data acquisition and wrote the first draft of the manuscript. WL, AD, Ts. K, and KS contributed to the statistical analysis. WL, To. K, and KS contributed to discussing, revising, and reading the manuscript. All authors approved the final version of the manuscript for submission.

Funding: The authors declare that the current study received funding from the Daikin Industries, Ltd. The funder was not involved in the study design, collection, analysis and interpretation of data, writing of the manuscript, or decision to submit the manuscript for publication.

Competing Interests: The authors declare no competing interests.

\section{References}

1. Li, L. \& Lin, T. T. C. Examining how dependence on smartphones at work relates to Chinese employees' workplace social capital, job performance, and smartphone addiction. Inf. Dev. 34, 489503 http://doi.org/10.1177/0266666917721735 (2018).

2. Neștian, Ș. A., Tiță, S. M. \& Turnea, E.-S. Using mobile phones at work in personal and professional information processes. Sustainability 12, 965 https://doi.org/10.3390/su12030965 (2020).

3. Byström, K., Ruthven, I. \& Heinström, J. Work and information: which workplace models still work in modern digital workplaces? Inf. Res. 22, CoLIS Paper 1651 (2017).

4. Zhou, J. \& Hoever, I. J. Research on Workplace creativity: a review and redirection. Annu. Rev. Organ. Psychol. Organ. Behav. 1, 333-359 http://doi.org/10.1146/annurev-orgpsych-031413-091226 (2014). 
5. Corazza, G. E. Organic creativity for well-being in the post-information society. Eur.S J. Psychol. 13, 599-605 http://doi.org/10.5964/ejop.v13i4.1547, 29358976 (2017).

6. Glăveanu, V. P., Ness, I. J. \& de Saint Laurent, C. Creativity, learning and technology: opportunities, challenges and new horizons. Creativity Res. J. 32, 1-3 https://doi.org/10.1080/10400419.2020.1712167 (2020).

7. Amabile, T. M. The social psychology of creativity: A componential conceptualization. J. Pers. Soc. Psychol. 45, 357-376 http://doi.org/10.1037/0022-3514.45.2.357 (1983).

8. Dul, J., Ceylan, C. \& Jaspers, F. Knowledge worker creativity and the role of the physical work environment. Hum. Resour. Manag. 50, 715-734 http://doi.org/10.1002/hrm.20454 (2011).

9. Ritter, S. M. \& Ferguson, S. Happy creativity: listening to happy music facilitates divergent thinking. PLOS ONE 12, e0182210, 1-14 http://doi.org/10.1371/journal.pone.0182210, 28877176 (2017).

10. Vohs, K. D., Redden, J. P. \& Rahinel, R. Physical order produces healthy choices, generosity, and conventionality, whereas disorder produces creativity. Psychol. Sci. 24, 1860-1867 http://doi.org/10.1177/0956797613480186, 23907542 (2013).

11. Guilford, J. P. The nature of human intelligence (McGraw-Hill, 1967).

12. Mehta, R., Zhu, R. J. \& Cheema, A. Is noise always bad? Exploring the effects of ambient noise on creative cognition. J. Con. Res. 39, 784-799 http://doi.org/10.1086/665048 (2012).

13. Zabelina, D. Attention and creativity in The Cambridge handbook of the neuroscience of creativity (eds. Vartanian, O. \& Jung, R.) 159-230 (Cambridge University Press, 2018).

14. Wiley, J. \& Jarosz, A. F. Working memory capacity, attentional focus, and problem solving. Curr. Dir. Psychol. Sci. 21, 258-262 http://doi.org/10.1177/0963721412447622 (2012).

15. Ansburg, P. I. \& Hill, K. Creative and analytic thinkers differ in their use of attentional resources. Pers. Individ. Dif. 34, 1141-1152 http://doi.org/10.1016/S0191-8869(02)00104-6 (2003).

16. Finke, R., Ward, T. B. \& Smith, S. M. Reviews in Creative cognition: theory, research and applications 238-247 (MIT Press, 1992).

17. Martindale, C. Creativity and connectionism in The creative cognition approach (eds. Smith, S. M., Ward, T. B. \& Finke, R. A.) 249-268 (MIT Press, 1995).

18. Rawlings, D. Psychoticism, creativity, and dichotic shadowing. Pers. Individ. Dif. 6, 737-742 http://doi.org/10.1016/0191-8869(85)90084-4 (1985).

19. Sharma, S. \& Babu, N. Interplay between creativity, executive function and working memory in middle-aged and older adults. Creat. Res. J. 29, 71-77 http://doi.org/10.1080/10400419.2017.1263512 (2017).

20. Wallach, M. \& Kogan, N. Modes of Thinking in Young Children (Holt, Rinehart \& Winston, 1965).

21. Torrance, E. The Torrance Tests of Creative Thinking-Norms-Technical Manual Research EditionVerbal Tests, Forms A and B- Figural Tests, Forms A and B (Personnel Press, 1974).

22. Miyake, A., Friedman, N.P., Emerson, M.J., Witzki, A.H., \& Howerter A. The unity and diversity of executive functions and their contributions to complex frontal lobe tasks: A latent variable analysis. 
Cogn. Psychol. 41, 49-100 http://doi.org/10.1006/cogp.1999.0734, 10945922 (2000).

23. Carson, S. H., Peterson, J. B. \& Higgins, D. M. Decreased latent inhibition is associated with increased creative achievement in high-functioning individuals. J. Pers. Soc. Psychol. 85, 499-506 http://doi.org/10.1037/0022-3514.85.3.499, 14498785 (2003).

24. Zmigrod, S., Zmigrod, L. \& Hommel, B. The relevance of the irrelevant: attentional distractor-response binding predicts performance in the remote associates task. Psychol. Aesthet. Creativity Arts 13, 1523 http://doi.org/10.1037/aca0000162 (2019).

25. May, C. P. Synchrony effects in cognition: the costs and a benefit. Psychon. Bull. Rev. 6, 142-147 http://doi.org/10.3758/bf03210822, 12199309 (1999).

26. Kim, S., Hasher, L. \& Zacks, R. T. Aging and a benefit of distractibility. Psychon. Bull. Rev. 14, 301305 http://doi.org/10.3758/BF03194068, 17694917 (2007).

27. Jarosz, A. F., Colflesh, G. J. \& Wiley, J. Uncorking the muse: alcohol intoxication facilitates creative problem solving. Conscious. Cogn. 21, 487-493 http://doi.org/10.1016/j.concog.2012.01.002, 22285424 (2012).

28. Mednick, S. A. The Remote Associates test. J. Creat. Behav. 2, 213-214 http://doi.org/10.1002/j.2162-6057.1968.tb00104.x (1968).

29. Cambier, R., Van Laethem, M. \& Vlerick, P. Private life telepressure and workplace cognitive failure among hospital nurses: the moderating role of mobile phone presence. J. Adv. Nurs. 76, 2618-2626 http://doi.org/10.1111/jan.14496, 32803902 (2020).

30. Ward, A. F., Duke, K., Gneezy, A. \& Bos, M. W. Brain drain: the mere presence of one's own smartphone reduces available cognitive capacity. Journal of the Association for Consumer Research 2, 140-154 http://doi.org/10.1086/691462 (2017).

31. Ito, M. \& Kawahara, J. I. Effect of the presence of a mobile phone during a spatial visual search. Jpn. Psychol. Res. 59, 188-198 http://doi.org/10.1111/jpr.12143 (2017).

32. Thornton, B., Faires, A., Robbins, M. \& Rollins, E. Mere presence of cell phone may be distracting. Soc. Psychol. 45, 479-488 http://doi.org/10.1027/1864-9335/a000216 (2014).

33. Stothart, C., Mitchum, A. \& Yehnert, C. The attentional cost of receiving a cell phone notification. J. Exp. Psychol. Hum. Percept. Perform. 41, 893-897 http://doi.org/10.1037/xhp0000100, 26121498 (2015).

34. Vorderer, P. \& Kohring, M. Permanently online: A challenge for media and communication research. Int. J. Commun. 7, 188-196 (2013).

35. Kaplan, S. The restorative effects of nature: towards an integrative frame-work. J. Environ. Psychol. 16, 169-182 http://doi.org/10.1016/0272-4944(95)90001-2 (1995).

36. Stevenson, M. P., Dewhurst, R., Schilhab, T. S. \& Bentsen, P. Cognitive restoration in children following exposure to nature: evidence from the Attention Network Task and mobile eye tracking. Front. Psychol. 10, e42 http://doi.org/10.3389/fpsyg.2019.00042, 30804825 (2019). 
37. Laumann, K., G.arling, T., \& Stormark, K. M. Selective attention and heart rate responses to natural and urban environments. Journal of Environmental Psychology, 23, 125-134 (2003).

38. Atchley, R. A., Strayer, D. L. \& Atchley, P. Creativity in the wild: improving creative reasoning through immersion in natural settings. PLOS ONE 7, e51474 http://doi.org/10.1371/journal.pone.0051474, 23251547 (2012).

39. Ferraro III, F. M. Enhancement of convergent creativity following a multiday wilderness experience. Ecopsychology 7, 7-11 http://doi.org/10.1089/eco.2014.0043 (2015).

40. Shibata, S. \& Suzuki, N. Effects of indoor plan on creative task performance and mood. Scand. J. Psychol. 45, 373-381 http://doi.org/10.1111/j.1467-9450.2004.00419.x, 15535806 (2004).

41. Alawad, A. Can we bring the natural environment into the art classroom? Can natural sound foster creativity? Educ. Res. Rev. 7, 627-631 http://doi.org/10.5897/ERR11.167 (2012).

42. Plambech, T. \& Konijnendijk van den Bosch, C. C. The impact of nature on creativity-a study among Danish creative professionals. Urb. For. Urb. Green 14, 255-263 (2015).

43. Ulrich, R. S. Aesthetic and affective response to natural environment in Behavior and the natural environment (ed. Altman, I. \& Wohlwill, J. F.) 85-125 (Plenum Press, 1983).

44. Ulrich, R. S. et al. Stress recovery during exposure to natural and urban environments. J. Environ. Psychol. 11, 201-230 http://doi.org/10.1016/S0272-4944(05)80184-7 (1991).

45. Bratman, G. N., Daily, G. C., Levy, B. J. \& Gross, J. J. The benefits of nature experience: improved affect and cognition. Landsc. Urban Plan. 138, 41-50 http://doi.org/10.1016/j.landurbplan.2015.02.005 (2015).

46. DeCaro, M. S., Van Stockum, C. A., Jr \& Wieth, M. B. When higher working memory capacity hinders insight. J. Exp. Psychol. Learn. Mem. Cogn. 42, 39-49 http://doi.org/10.1037/xlm0000152, 26120772 (2016).

47. Braithwaite, J. J., Watson, D. G., Jones, R. \& Rowe, M. A guide for analysing electrodermal activity (EDA) \& Skin Conductance Responses (SCRs) for psychological experiments (University of Birmingham, 2013).

48. Orita, R., Hattori, M. \& Nishida, Y. Development of a Japanese Remote Associates Task as insight problems. Jpn. J. Psychol. 89, 376-386 http://doi.org/10.4992/jjpsy.89.17201 (2018).

49. Watson, D., Clark, L. A. \& Tellegen, A. Development and validation of brief measures of positive and negative affect: the Panas scales. J. Pers. Soc. Psychol. 54, 1063-1070 http://doi.org/10.1037//0022-3514.54.6.1063, 3397865 (1988).

50. Sato, A. \& Yasuda, A. Development of the Japanese version of Positive and Negative Affect Schedule (PANAS) scales. Japanese Journal of Personality 9, 138-139 http://doi.org/10.2132/jjpjspp.9.2_138 (2001).

51. Russell, J. A. A circumplex model of affect. J. Pers. Soc. Psychol. 39, 1161-1178 http://doi.org/10.1037/h0077714 (1980). 
52. Miyake, S. \& Kumashiro, M. Subjective mental workload assessment technique-an introduction to NASA-TLX and SWAT and a proposal of simple scoring methods. Jpn. J. Ergon. 29, 399-408. (in Japanese) (1993).

53. Hart, S. G. \& Staveland, L. E. Development of NASA-TLX (Task Load Index): results of empirical and theoretical research in Human Mental Workload (eds. Hancock, P. A. \& Meshkati, N.) 139-183 (NorthHolland Press, 1988).

54. Merlo, L. J., Stone, A. M. \& Bibbey, A. Measuring problematic mobile phone use: development and preliminary psychometric properties of the PUMP scale. J. Addict. 2013, 912807 http://doi.org/10.1155/2013/912807, 24826371 (2013).

55. El-Sheikh, M., Keller, P. S. \& Erath, S. A. Marital conflict and risk for child maladjustment over time: skin conductance level reactivity as a vulnerability factor. J. Abnorm. Child Psychol. 35, 715-727 http://doi.org/10.1007/s10802-007-9127-2 (2007).

56. Clark, A. Natural-born cyborgs: Minds, technologies, and the future of human intelligence (Oxford University Press, 2003).

57. Brich, I.R., Bause, I.M., Hesse, F.W. \& Wesslein, A.K. How spatial information structuring in an interactive technological environment affects decision performance under working memory load. Comput. Hum. Behav. 123 https://doi.org/10.1016/j.chb.2021.106860 (2021).

58. Liu, W. J., Kitamura, A. \& Sinohara, K. Characteristics of distraction caused by the presence of a smartphone in workplace. Jpn. J. Ergon. 57, 203-207 (2021).

59. Tanil, C. T. \& Yong, M. H. Mobile phones: the effect of its presence on learning and memory. PLOS ONE 15, e0219233 http://doi.org/10.1371/journal.pone.0219233, 32790667 (2020).

60. Johannes, N., Veling, H., Verwijmeren, T. \& Buijzen, M. Hard to resist? The effect of smartphone visibility and notifications on response inhibition. J. Media Psychol. Theor. Methods Appl. 31, 214225 (2019).

61. Crowley, J. P., Allred, R. J., Follon, J. \& Volkmer, C. Replication of the mere presence hypothesis: the effects of cell phones on face-to-face conversations. Commun. Stud. 69, 283-293 http://doi.org/10.1080/10510974.2018.1467941 (2018).

62. Hartmann, M., Martarelli, C. S., Reber, T. P. \& Rothen, N. Does a smartphone on the desk drain our brain? No evidence of cognitive costs due to smartphone presence in a short-term and prospective memory task. Conscious. Cogn. 86, 103033 http://doi.org/10.1016/j.concog.2020.103033, 33137560 (2020).

63. Linares, C. \& Sellier, A. L. How bad is the mere presence of a phone? A replication of Przybylski and Weinstein (2013) and an extension to creativity. PLOS ONE 16, e0251451 http://doi.org/10.1371/journal.pone.0251451, 34106931 (2021).

64. Bratman G.N., Daily G.C., Levy B.J., Gross J.J. The benefits of nature experience: improved affect and cognition. Landsc Urban Plan 138, 41-50 https://doi:10.1016/j.landurbplan.2015.02.005 (2015).

65. Dorfman, L., Martindale, C., Gassimova, V., Vartanian O. Creativity and speed of information processing: A double dissociation involving elementary versus inhibitory cognitive tasks. Pers. 
Individ. Differ. 44, 1382-1390 https://doi.org/10.1016/j.paid.2007.12.006 (2008).

66. Mednick, S. A. The associative basis of the creative process. Psychol. Rev. 69, 220-232 http://doi.org/10.1037/h0048850, 14472013 (1962).

\section{Figures}

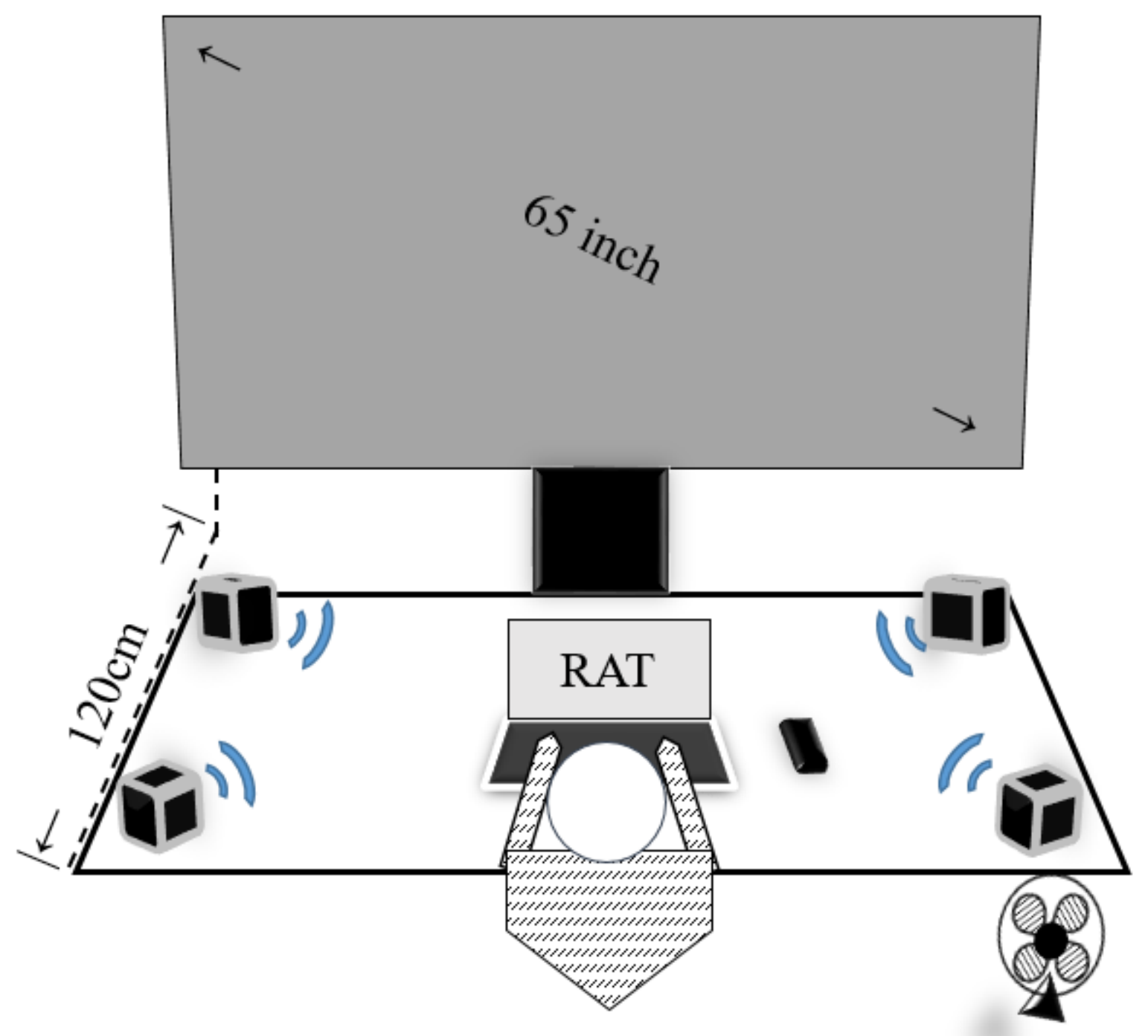

Figure 1

The experimental environment. 


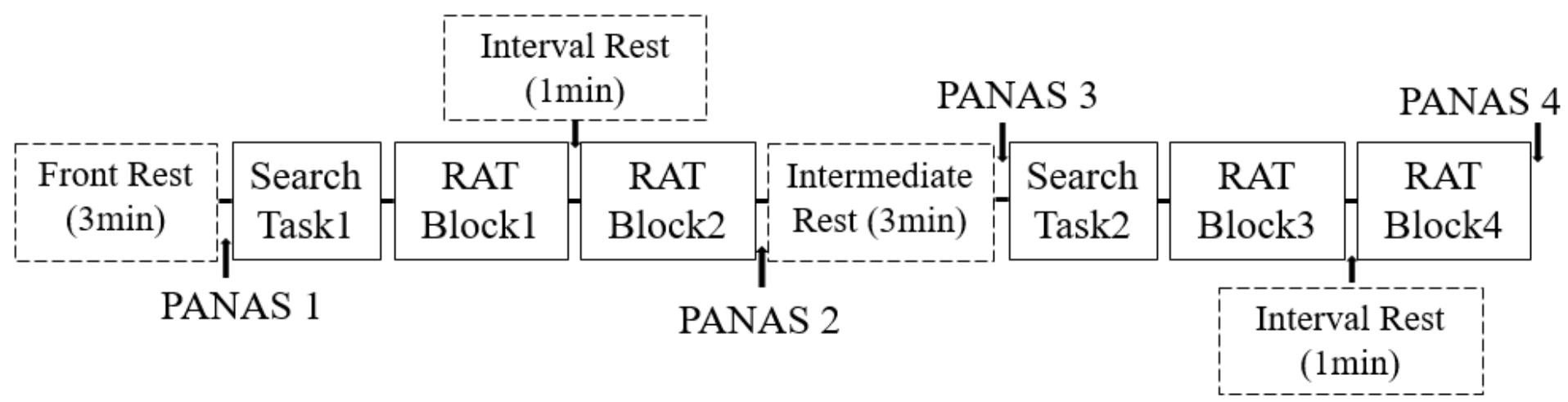

Figure 2

The sequence of single day's experiment.

a $\quad \square$ Nature absence $\square$ Nature presence

b $\square$ Nature absence $\square$ Nature presence

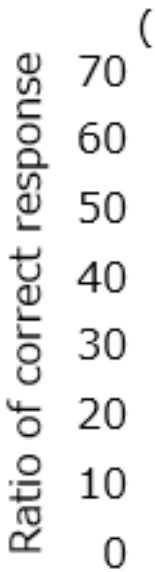
$(\%)$
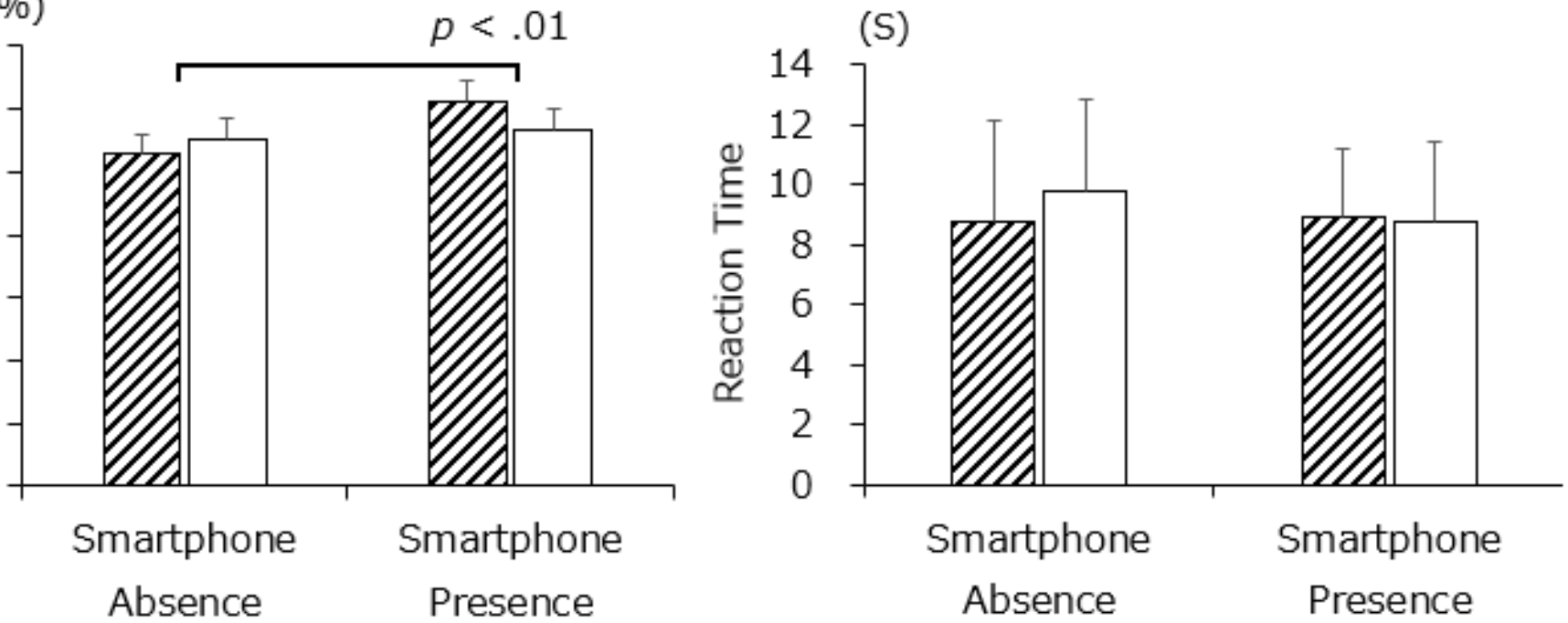

Figure 3

Ratios of a. correct RAT response and b. reaction time. Error bars depict standard error values. 


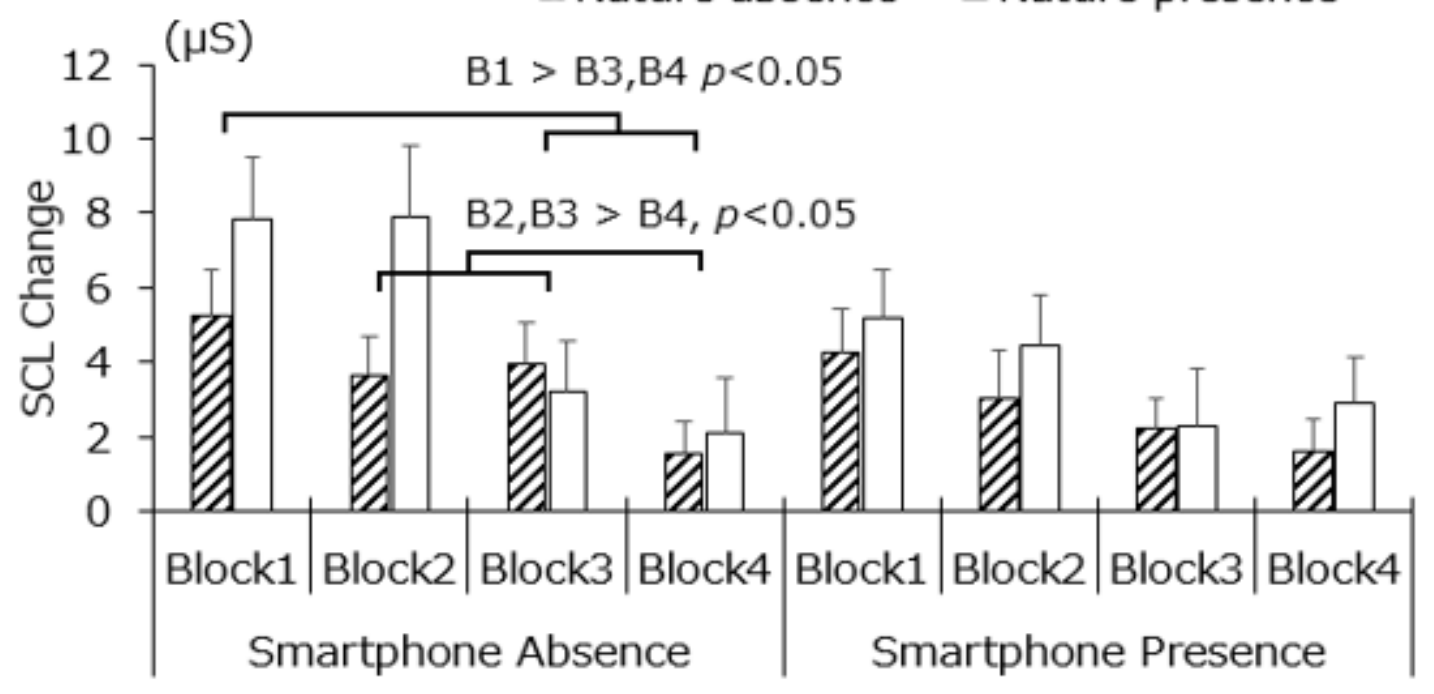

Figure 4

SCL changes. Error bars depict standard error values.

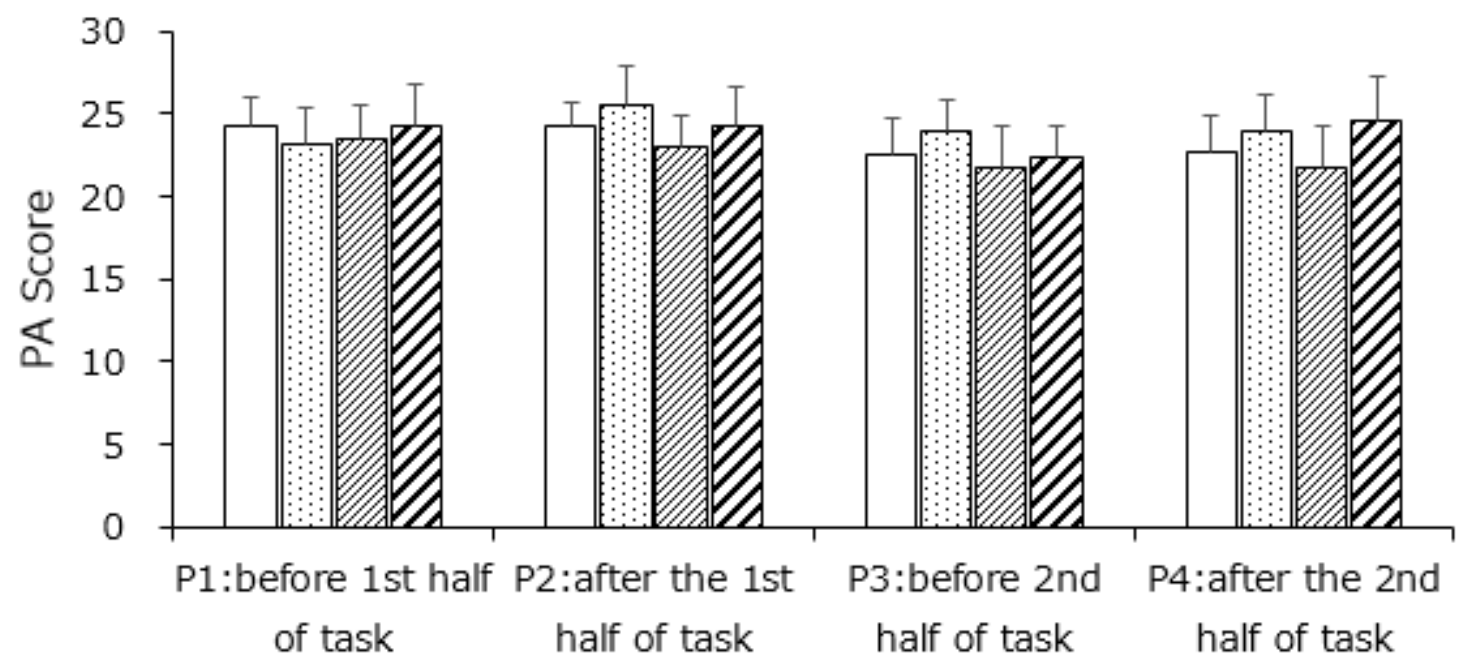

$\square$ Nature absence Mobile-battery $\square$ Nature absence Smartphone nature presence Mobile-battery $\square$ Nature presence Smartphone

\section{Figure 5}

Mean positive affect scores. Error bars depict standard error values. 


$$
\mathrm{P} 3, \mathrm{P} 4<\mathrm{P} 2 ; p<.05
$$

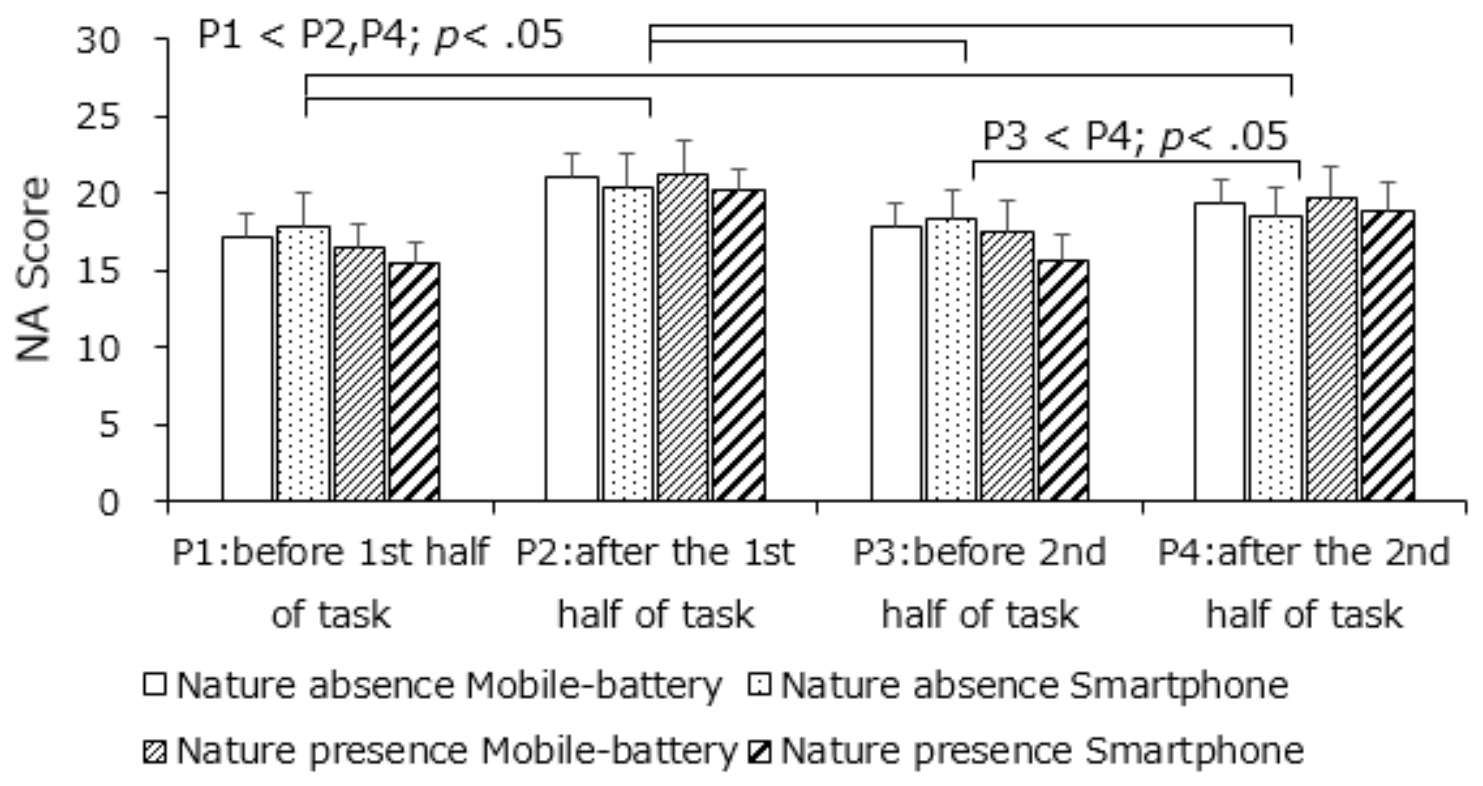

\section{Figure 6}

Mean negative affect scores (lower). Error bars depict standard error values. 
a

Valence

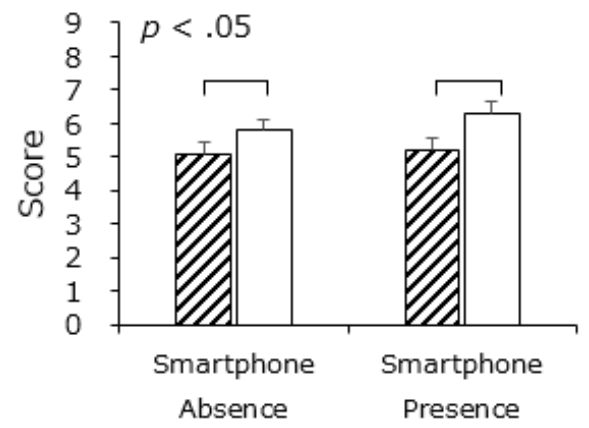

$\square$ Nature absence $\square$ Nature presence b

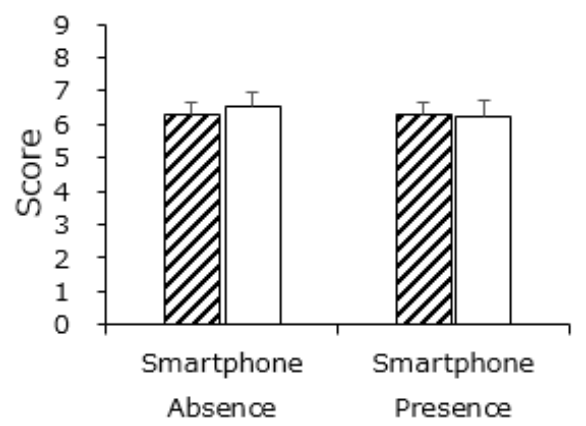

$\square$ Nature absence $\square$ Nature presence c Desire of Knowledge

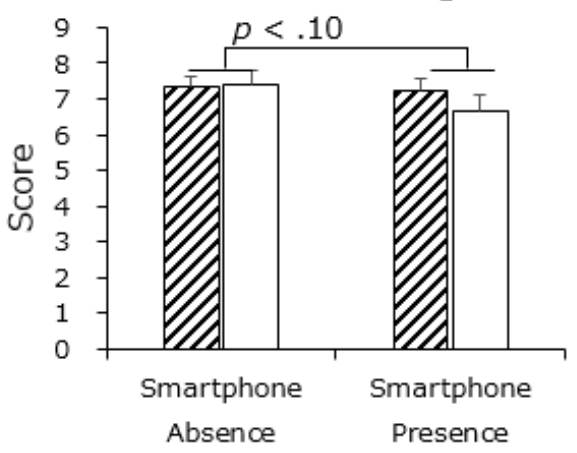

$\square$ Nature absence $\square$ Nature presence

f

Frustration

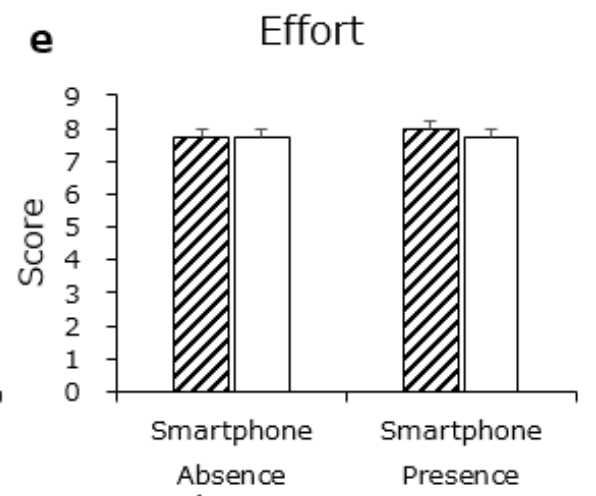

Absence

Presence

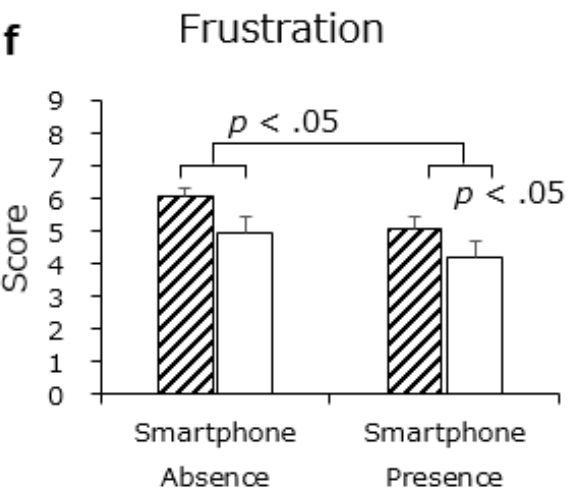

Smartphone

Absence

$\square$ Nature absence $\square$ Nature presence

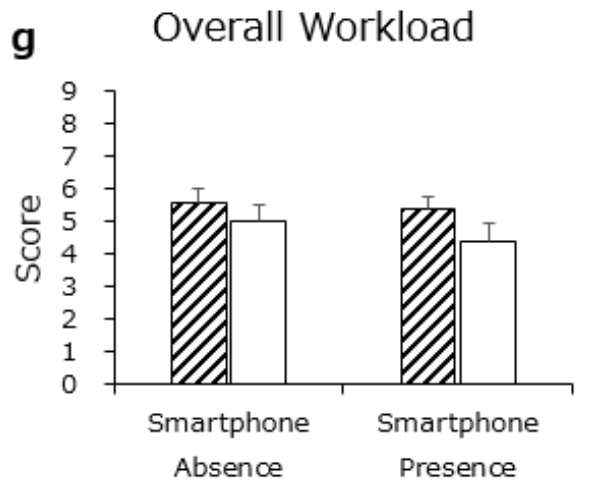

Z Nature absence $\square$ Nature presence

\section{Figure 7}

Mean subjective evaluations: a: valence, b: arousal, c: desire of knowledge, d: own performance, e: effort, f: frustration, and g: overall workload. Error bars depict standard error values. 